\title{
Global Justice and the Priority of Basic Goods to Basic Freedoms: Reflexions on Amartya Sen's Development and Freedom*
}

\author{
Mario SoLÍS UMAÑA
}

Recibido: 16 de septiembre de 2011

Aceptado: 27 de marzo de 2012

\begin{abstract}
The paper examines Amartya Sen's seminal work Development and Freedom (1999) in relation to his underlying conception of justice and particularly in relation to the tension that arises in the correlation between basic freedom and basic goods. The idea is to address the question as to which of the two elements (basic goods or basic freedoms) takes precedence to the enactment of global justice. The paper advances a particular distinction between a foundational approach and a functional approach when addressing the question of the priority and primacy of any of the two elements and sheds light on a contentious answer, namely, that basic goods are foundationally primary in relation to basic freedoms and that such a primacy does not rule out the functional priority of basic freedoms.
\end{abstract}

Keywords: Freedom, development, social justice, global justice, basic goods, priority problem.

\section{Introduction}

One of the most important challenges to any theory of global justice is not so much about the inclusion of the value of freedom alongside the concern about the

\footnotetext{
* I thank the audience at Bryn Mawr College (in the $9^{\text {th }}$ International IDEA Conference) for helpful comments and particularly to David Crocker, Jay Drydyk and Nigel Dower for their suggestions and support.
} 
material conditions for everybody to lead a dignified life plan (basic goods), but about the tension that arises in the correlation between basic freedoms and basic goods and the question about interconnectedness that is being posed by the complexity of this interaction. This complex correlation may be best observed in the relationship between freedom and development, as instructively set out by Amartya Sen in his seminal work Development and Freedom (1999).

It is my contention that it is not enough to say that basic goods and basic freedoms constitute the whole of global justice without accounting for the tensions and conflicts that arise in such a composition. Correlatively, it is also pertinent in my opinion to critically address the common tendency of looking at a sort of politicalinstitutional and logical primacy of political freedoms in the form of political (negative) rights in detriment to social (positive) rights. With all of this in mind, the paper inspects the combination of basic goods and basic freedoms that serves as the basis to defending the idea of global justice (particularly the contentious idea that the best approach to global justice comes down to a defence of the fundamental demand of reaching what I have called the sufficiency threshold).

In drawing on Amartya Sen's seminal work Development and Freedom (1999), this paper argues for (a) the primacy of basic rights along the lines of a functionaldifferentiation approach and (b) for the primacy of basic goods along the lines of a foundational-differentiation approach. In other words, to the question as to which of the two elements (basic goods or basic freedoms) takes precedence to the enactment of social justice, the proposed answer defends the priority of basic freedoms over basic goods. And to the question as to which of those elements provides the foundations to which, the proposed answer defends the claim that basic goods are foundationally primary in relation to basic freedoms and that such a primacy does not rule out the functional primacy of basic freedoms. The focus of the paper, however, is not so much on the proposed answers, but rather on the distinctions at hand. The idea is to see whether such a notional framework is sound, useful and coherent to account for the interconnectedness of basic goods and basic freedoms.

The paper is organized as follows. Part I provides a general description of the idea of global justice that is at the background of our concern about the seriality or lexicality order of basic goods and basic freedoms. Part II addresses the basic distinctions between a functional and foundational approach to basic goods in order to examine the thesis of the primacy of basic goods over basic freedoms. Part III focuses attention on the reach and scope of the aforementioned distinctions and judges them against the background of Sen's thesis of development as freedom. This part explores Sen's claims about the instrumental and constructive role of freedom, and most importantly, his central claim that freedom is the primary end and the principal means of development. Here the paper states the view of the priority of basic freedoms in functional terms and the correlative (non-contradictory) view 
of the primacy of basic goods in foundational terms. Part IV concludes the paper by drawing attention to how strong can the thesis of the primacy of basic goods over basic freedoms be (the concreteness of the former, the relative flexibility of the latter) and by highlighting both the distinctiveness and the interconnectedness of basic goods and basic freedoms.

Before moving on, some clarifications regarding the idea of global justice are in order. This is because such a notion constitutes the framework in which the tension between basic goods and basic freedoms will be examined.

Notice, for a start, that it is not clear today what a theory of global justice should be like. A great number of political philosophers and social scientists are repeatedly drawing attention to the fact that theories of global justice are in their infancy. Charles Beitz, one of the proactive voices in the debate, recalls this fact and stresses the importance of working out a clearer and effective political and intellectual framework for this pressing matter. Beitz asserts that "[...] at first glance, it is not clear that there is any subject for global political justice to be about. And even if one discerns a subject, it is not clear how to proceed..." and later he adds "[...] I do not believe there is any more urgent preoccupation for political philosophy today than to work out a better theoretical understanding of these matters of global justice." (2005: 25-27). Thomas Nagel also points to the incipient status of global justice and the moral and political importance of engaging in such a debate. "[...] Concepts and theories of global justice" Nagel asserts "are in the early stages of formation and it is not clear what the main questions are, let alone the main possible answers" (2005: 113). Other prominent contemporary philosophers such as Leif Wenar have suggested that global justice is indeed a "nascent academic sub-discipline" (Wenar, 2007: 106).

As we can infer from the aforementioned remarks, it is not the main objective of this paper to offer a particular theory of global justice, and therefore I will not try an independent argument in this regard. It suffices to point out to what can be considered the fundamental demand for global justice: the requirement to ensure that everybody has enough to lead a dignified life, (that is, enough to meet what I called elsewhere the sufficiency threshold). It is my contention that the best approach to global justice comes down to a defence of this fundamental demand-a demand that may well be seen as commonsensical or not particularly over-demanding at the national level.

Global justice entails not only 'basic goods as such', to use a simple expression, but also a qualitative dimension in basic goods. If we talk about global justice solely in terms of basic goods, then there is the danger of missing the fact that goods in 
themselves (if there are truly such things) are nothing but elements that create a condition of life. Similarly, if we talk about global justice solely in terms of a standard, it becomes a too loose and ambiguous approach: only when a standard contains a strict account of the goods does it have a reasonably objective meaning. A convincing approach to global justice should thus be the combination of these two elements (Sen's capability approach is very instructive in this sense and appropriate as a theoretical framework for global justice) $)^{1}$.

The idea of global justice is also related to this very topical debate: the cosmopolitanism/anti-cosmopolitanism debate. As a matter of background, it is worth to notice the sense in which cosmopolitanism should be understood. Cosmopolitanism is the name of an emerging theoretical approach to moral and political issues that seems to go beyond the realms of nation-states and the realm of state-system based international relations. Thus far, cosmopolitanism is subdivided into two categories, with most philosophers and political theorists distinguishing between moral and political-institutional cosmopolitanism (Beitz, 1999: 298; Pogge, 2002: 170).

This distinction is already a central aspect of the global social justice debate. Moral cosmopolitanism, as David Miller points out, "says simply that human beings are all subject to the same set of moral laws" (Miller, 2007: 24). In other words, moral cosmopolitans are those who hold the view that, as Simon Caney puts it, "there is no morally fundamental significant difference between the domestic and the global realms" (Caney, 2005: 265)2. Political-institutional cosmopolitanism, on the other hand, is commonly related to questions concerning the system of institutions that shape our collective existence. The debate about global justice and cosmopolitanism that is in the background of this paper strictly evokes political-institutional cosmopolitanism.

\section{II}

Having said all this let me address the particular issue at hand. It seems accurate to claim that basic freedoms should be thought of as necessary conditions (though not sufficient) for accessing basic goods and vice versa. This is the interconnectedness claim.

One might want to argue that basic freedoms are a constitutive part of subsistence or that they are absolutely indistinguishable from subsistence. This may be

\footnotetext{
1 See Amartya Sen's recent work The idea of Justice (2009).

2 Thomas Nagel also identifies cosmopolitanism with a moral approach that he calls monism, following Liam Murphy's terminology used in "Institutions and the Demands of Justice" (1998). See Nagel 2005: 122-123.
} 
called the co-substantiality approach. On this approach, the relationship between basic goods and basic freedoms is of little importance since, for instance, basic freedoms would be assumed simply as substantive goods absolutely equivalent to basic (subsistence) goods.

Without going into the details regarding the possible objections to this approach at this point, it seems to me that its simplicity is of a negative kind. It has the tendency to overlook the specificity of basic goods and basic freedoms when the question of priority arises, having thus a potentially negative effect both on the understanding and undertaking of fairer public policies. The co-substantiality approach is also too weak an account of the theoretical difficulties surrounding the themes of domestic and global social justice.

The evident alternative is to claim that basic freedoms and basic goods are distinctive categories. Let me call this the differential approach. This approach is twofold: basic goods and basic freedoms are differentiable in their functional and foundational features. Each of these two variants of the differential approach poses a particular form of interconnection between basic goods and basic freedoms.

The dispute along the lines of the functional difference relates to the issue of priority. It is about the question as to which of the two elements (basic goods or basic freedoms) takes precedence to the enactment of global justice. There are obviously three possibilities here: (a) the priority of basic goods over basic freedoms, (b) the priority of basic freedoms over basic goods, and (c) the non-priority possibility (i.e., both elements go hand in hand).

The second dispute concerning the foundational difference is set out in terms of the grounding value rather than in terms of enactment. This variant asks the question as to which of those elements provides the foundations to which. There are two options here: either basic goods (needs) are primary in relation to basic freedoms or the opposite (a third possibility here would be to assume the inapplicability of the problem but this might be too much of an easy way out. It amounts to the co-substantiality thesis). In what follows I intend to shed light on the pertinence of the distinctions above and propose some answers to these questions.

\section{III}

As just mentioned, Amartya Sen (1999) provides a very suggestive analysis of the relationship between development and freedom that helps bringing to light the above alternatives, thus contributing to the aim of providing a more comprehensive account global justice in line of the sufficiency threshold claim. I shall draw on his views to this effect. 
Consider firstly some preliminary remarks. Sen's general view of social justice in terms of capabilities (or substantive freedoms to function as fully-fledged human beings) exhibits to a great extent the rationale of the sufficiency threshold thesis mentioned earlier. The capability approach is not about defending what people have in a fetishist fashion: it is not about the means of living as if that was all that matters to tackle poverty and injustice (it is not strictly a metric of equality and justice) ${ }^{3}$. I adopt Sen's idea of the importance of functioning and capabilities as opposed to the sometimes overemphasised 'commodity views' in the pursuit of justice.

Sen provides a robust account of freedom as development that rightly shows the importance of scrutinizing any development policy not only in terms of economic measures (purely financial calculations) but in terms of human development. It is about aiming at the well-being of individuals rather than the economy. Sen thus claims that we should broaden our analysis (and demands) from the basic idea of "means of living" to the "actual living", to "the freedom to achieve actual livings that one can have reason to value (Sen, 1999: 72-73)" 4 . This broadening is reflected in his assessment of (human) development as (substantive) freedom. For him, development (we might say here justice) is seen as "a process of expanding substantive freedoms that people enjoy", which firstly, but not uniquely, must start with the overcoming of systematic material deprivation (Ibid: 3 ).

This is a convincing stance that is both theoretically informed and suggestive as an instrument for public policy and institutional design (as discussed in the final chapters of this study). In including basic freedoms as part of the bundle of basic goods that the claims for global justice enclose, I am sharing the spirit of such views and some of its salient corollaries. Claiming for global justice is not defending the conventional wisdom in regard to basic goods as simply means for subsistence or of a transitory remedy against injustice -commonly seen in paternalistic (assistance-like) public policies around the world. By contrast, securing basic goods together with basic freedoms (the sufficiency threshold) should be seen as the heart of the demands for global justice, demands that call upon the negation of systemic deprivation 5 .

Having said this let me now focus attention on the aforementioned differential approach and judge it against the background of Sen's thesis of development and

\footnotetext{
3 See Sen's "Equality of What" (1979) and the vast literature that followed in relation to the currency and metric of equality.

${ }^{4}$ Sen submits that Rawls's idea of primary goods goes beyond the simplistic emphasis on income, but he also maintains that Rawls's view is still limited insofar as it is still a sort of 'resourcist' account (to the extent of which it emphasises the idea of 'means' in defining primary goods as "general purpose means"). I disagree with this interpretation. I think Rawls' account (and his idea of 'means') is richer than Sen's takes it to be, but I am not pursuing this matter here.

5 For a detailed defence of the rationale of the sufficiency threshold in connection with systemic deprivation, see the coming chapter, section II.
} 
freedom. To do this, I need to qualify those two categories (development and freedom). As hinted above, development and freedom can be thought of in a wider sense, i.e., in the wider sense of substantive freedom and human development (as Sen does) and in narrow sense, i.e., development according to the development index (in terms of nutrition, infant mortality, access to health, education, decent housing, etc.) and freedom as political participation, free press, transparency, and accountability. As already mentioned, I am sympathetic to Sen's wider account. However, I think that his general account is in some ways too close to the co-substantiality approach. In trying to address the differential approach, I am also trying to move from the wide to the narrow version of development and freedom. This is more compatible with the 'minimalistic' variables necessary to account for the demands of global justice - the variables being basic goods and basic freedoms, the demand: to ensure that everybody has enough to lead a dignified life. In this direction, development stands for subsistence goods and freedom for political rights stricto sensu.

So therefore, my interpretative proposal stresses the specificity of basic goods and basic freedoms and thus raises the question of priority and primacy of any of the two different variables in question (this is against the co-substantiality approach mentioned earlier in the paper and in view of the particularly relevant task of making sense of the idea of global justice). Let us go on to see the details of the difference and connectivity of basic goods and basic freedoms in the light of Sen's central idea of Development as Freedom.

Sen's central claim is that freedom is "the primary end and the principal means of development" (Sen, 1999: 36). The primacy (Sen also uses the term pre-eminence) of freedom is argued for in a set of three arguments:

1) its direct importance in human living associated with basic capabilities (including that of political and social participation);

2) its instrumental role in enhancing the hearing that people get in expressing and supporting their claims to political attention (including the claims of economic needs);

3 ) its constructive role in the conceptualization of 'needs' (including the understanding of 'economic needs' in a social context) (Ibid: 148).

It seems to me that the arguments (2) and (3) for the primacy of freedom, as they stand, can be understood along the lines of the functional approach; and these arguments, as discussed below, are mostly pointing towards the second alternative in the functional approach, i.e., the priority of freedom (rather than towards the opposite) ${ }^{6}$.

${ }^{6}$ This is a general approach to the question. This position does not bar us from supporting the non-priority thesis once we move from this level of abstraction to the concrete level of contextualized institutional practices. 
From a technical point of view (which mostly targets the orthodox views of development in economics), the priority of freedom is concerned with democratic debate and decision-making made through public choice and should come first as a matter of efficiency and plausibility. Free exchange of views and opinion in the public space is the key to development and, by opposition, the lack of freedom would make any public policy for development a recipe for failure, in spite of the accuracy of the economic procedures 7 . Expert calculations alone, however brilliant, can hardly work towards the desired ends of global justice, i.e. the eradication of poverty (or in the language of Sen, the eradication of capability deprivation). We need to bring forward "the understanding of economic needs in a social context" and the public "conceptualization of needs" that arises out of substantive political freedoms as the primary means for development and social justice (Ibid: 148). This is why development as freedom as examined in Sen's work is set out as a petition for a more robust approach to developmental polices that go beyond the question of resources and pure economic welfare. Such policies should be set out with consideration to the priority of freedom.

From the political-institutional (historical) point of view, the priority of freedom is expressed in Sen's well-known empirical claim that large-scale famines do not happen in a democracy: "no substantial famines have ever occurred in any independent country with a democratic from of government and a relatively free press" (Ibid: 152) ${ }^{8}$. In looking after the political freedoms and the protection of civic freedoms, a democratic regime will provide the security and the necessary pre-emptive measures to tackle absolute deprivation. This does not happen, Sen argues, in authoritarian regimes (Ibid: 16). Again, the functionally primary character of political freedom seems socially warranted (as they "induce social responses to economic needs") and epistemologically empowering, i.e., "central to the conceptualization of economic needs" (Ibid: 154, my emphasis). Freedom is therefore a pre-condition of economic growth (narrow view of basic goods) and human development (wider view of basic goods).

What about Sen's argument (1)? Compared to the other two arguments, this one is clearly harder to grasp. Sen does not give us a detailed characterization of the argument. We then need to provide some extra considerations 9 . The argument, to

\footnotetext{
${ }^{7}$ Sen provides relevant public policy insights to illustrate his claims. For instance, in relation to development related to reducing infant mortality, he suggests that public policies should empower women through literacy and employment as a matter of efficacy in this area -let alone as a matter of humanity or proper political morality (see chapter 8 of Sen's Development as Freedom).

8 Sen offered a detailed analysis of this topic in Poverty and Famines (1981).

9 Sen dedicates one paragraph to this argument (p. 152). The problem seems to be that Sen 'hesitates' between the idea of the pre-eminence of political freedoms (his argument here) and the alternative thesis of co-substantiality. In this paragraph, he seems to be defending basic freedoms as part of basic capabilities ("the importance of political freedoms as part of basic capabilities has already been dis-
} 
recall, is that political freedoms are primordial in virtue of the "direct importance in human living associated with basic capabilities (including that of political and social participation)" (Ibid, 148). Notice that Sen also uses the more familiar notion (in the family of moral and political philosophy) of intrinsic value as synonymous with "direct importance"10. Unsurprisingly, argument (1) is particularly related to the foundational approach and certainly more open-ended precisely because it has to do with such a controversial 'property of intrinsicness'.

Understood in plain terms, the claim that freedoms have intrinsic value is not mysterious. It is simply (and significantly) asserting that every type of freedom -freedom of political participation, freedom of dissent, etc.- is valuable in itself11. What is more, it does not seem odd to think, the way Sen presents it, that those freedoms are both a basic constituent of development as well as an instrument for development (an enabling condition). This is what the interconnectedness claim reflects and what a convincing conception of global justice is supposed to embrace.

However, there is a more subtle sense in which the property of intrinsicness may be approached. This happens when we relate the question of intrinsicness (as nonderivative) to the questions concerning foundations. It is the question as to which of the two elements in correlation constitutes the grounds of social justice. In this case the elements are development and freedom in a general sense and basic goods and basic rights more specifically.

Again, it might be argued that we should drop this opposition and adjudicate a constitutive (non-derivative) value to both basic goods and basic freedoms in relation to social justice; or that we should simply disregard the question concerning constitutive elements. I think that such an option is unsatisfactory. The best option is to engage with this question to further clarify the lines of the debate and the contesting view points therein. Here is where the division of labour between the foundational and the functional approach become useful.

In relation to Sen's three claims stated above, the trick is to establish that claims (2) and (3) are particularly about a functional differentiation between basic freedoms and basic goods (and only indirectly may be used to address the foundational question). By contrast, claim (1) is particularly about a foundational differentiation that cannot be put on a par with the question relating to function. In this way, we may avoid the possible contradiction between the instrumental value of freedom

cuss in the earlier chapter", Sen says in this same paragraph.). I want to leave aside this ambiguity and take Sen's view as a defence of the logical and social primacy of 'political' freedoms, as the book implicitly suggests (especially chapters 1,3 and 6).

10 In fact, Sen uses this term in the chapter 'Culture and Human Rights', in a concluding remark. He says: "The case for basic freedoms and for the associated formulations in terms of rights rests on: 1) their intrinsic value, 2) their consequential role [...] 3) their constructive role [...]" (Sen, 1999: 246). 11 An example of this rather general claim is this: while education is valued originally for its contribution to job-seeking, over time it comes to be valued for itself. 
as stated in (2) and (3) and the intrinsic value of freedom as stated in (1). What is more, we ca also bring to the fore a clearer division of labour between basic goods and basic freedoms, thus facilitating a more convincing answer to the priority problem in this matter.

Once we distinguish these two types of questions and put together basic goods and basic freedoms along the lines of the functional approach, we may try to answer the question just mentioned: which of the two, basic goods or basic freedoms, is primary? In my interpretation of Sen's Development as Freedom, the answer seems ambiguous. We may be fairly sure that freedom is functionally primary. However, in foundational terms, the primacy of freedom over basic goods (or vice versa) is not so clear. Certainly the foundation of freedom and development is constituted by every particular human being as free agents; free agents are the "constitutive part" of freedom and development (Ibid: 4). However, this assertion, as important as it is, does not solve the question concerning the interaction of development and freedom, in the relationship between basic goods and basic rights.

Sen seems to be more inclined to the view that development (in the narrow sense) is primary in relation to freedom (also in the narrow sense). For a start, the consequential and constructive role of freedom (claims (2) and (3)) seem to point towards the primacy of basic goods. These second and third considerations (the instrumental and constructive roles of political freedoms) evidently serve the purpose of basic goods (satisfying basic needs) as Sen's very own phrasing shows. Basic freedoms are relevant to the extent that they give people the 'voice' to claim for economic needs (basic goods) and help in the crucial task of conceptualizing needs (Ibid: 148). The satisfaction of basic needs is one of the consequences of having in place (or shaping) effective and legitimate political-institutional structures protecting and securing the goods and rights we require for enacting global justice12. Evidently, in line with this interpretation, Sen's Development as Freedom may be assumed as one valuable philosophical (and political-economic) view from which some of the relevant features of the idea of global justice as reaching the sufficiency threshold can be found.

In commenting on Rawls's lexically prior liberty principle in the third chapter of his book ('Freedom and the Foundations of Justice'), Sen recognizes the comparatively "moderate" formulation of such a principle as opposed to the more extreme approach of Nozick whereby the precedence of the political over "the pursuit of social goals" is uncompromisingly advocated $(1999,63)$. I agree with Sen's read-

\footnotetext{
12 Considering the distinctive notions of development and freedom, particularly in the narrow sense (subsistence goods and political-institutional freedom respectively), one may rather change the phrase 'development as freedom' (and the implication of freedom as absolutely primary) with 'development in freedom'. Among the advantages of the latter formulation is that such a statement not only is less demanding, but also may better reflect the demands of social justice as ST.
} 
ing of Rawls in this respect and I think we can take the same criterion to interpret Sen's thesis of the primacy of (political) freedoms from the standpoint of the foundational approach. Basic freedoms should not be seen as preceding basic goods but as sanctioning those basic goods (the satisfaction of basic needs). Stating Sen's claim in the comparatively moderate fashion as hinted above gives weight to his own valid concerns about the 'economisation' of the notion of development and, at the same time, gives room to a more balanced account of the interconnectedness of freedoms and goods.

This more balanced account can also be seen in Sen's recent work The Idea of Justice (2009), particularly in his critique of Rawls's “transcendental institutionalism". In contrast to his comparative approach, Sen discusses the problems of feasibility and redundancy of any transcendental solution to the problem of justice, and points towards the flaws of an "arranged-focused view of justice" as opposed to " $a$ realization-focused understanding of justice" (2009: 9-10). This difference in perspective (being the second perspective one of the main features of Sen's capabilities' approach) reveals by itself the likelihood of my interpretation of the functional priority of freedom and confirms the distance Sen takes from Nozick's extreme formulation of the priority of Rawls's liberty principle or the idea of the absolute priority of the liberty principle. As he puts it: "Giving a special place -a general preeminence - to liberty goes well beyond taking note of the importance of liberty as one of many influences on a person's overall advantage. Liberty is indeed useful, like income and other primary goods, but that is not all that is involved in the importance of liberty... (Sen, 2009: 299)"

\section{IV}

Evidently, the above interpretation of Sen's ordering of freedoms and basic goods 'to be able to do and be what 'every one has reason to value' '-or that which Rawls called "primary goods" as 'all purpose means' to advance people's ends- is closely related to the contesting claim of the foundational primacy of basic goods over basic freedoms I am trying to point at.

Theoretically, form the standpoint of Rawls's theory of justice, this claim is warranted on his own thesis of the lexically prior basic goods principle found in Political Liberalism (1996), where Rawls recognizes the primordial character of basic goods in virtue of their role as a crucial medium for social relations (basic goods as primary even in relation to his two principles of justice).

From the standpoint of Sen's work, as already argued, this claim of the primacy of basic goods is warranted on the interpretation that I have already suggested, namely that freedoms are functionally prior to basic goods -which means that free- 
doms are to be defended in pursue of people's well-being; and correlatively, that basic goods are at the basis of any defence of the idea of freedom.

This paper has intended to offer a particular setting whereby one may defend the view that basic goods are primary in relation to basic freedoms. Admittedly, the idea of primacy (or even the image of grounding) can be improved. We might say that basic freedoms are anchored in basic goods. The allegorical term anchoring may well best capture both distinctiveness and interconnectedness between basic goods and basic freedoms. In any case, this position reflects the particular steadiness (or concreteness) of basic goods in comparison to the relative flexibility of basic freedoms. Basic freedoms involve a larger variety of factors ranging from those implied in the comprehensive category of the good to very particular events in the current history of each society.

This is not necessarily the case with basic goods (especially in the form of subsistence goods). All things considered and leaving aside the cases where someone decides to undertake a hunger strike to protest for certain causes -which may include the cause of providing basic goods for those who most need them-, we might allow constraining our basic freedoms under some very special circumstances, but we should not disregard our most basic needs. Sen has very recently made this point by posing the following question: "Why must any violation of liberty, significant as it is, invariably be judged to be more crucial for a person-or for a society- than suffering from intense hunger, starvation, epidemic and other calamities? (my emphasis Sen, 2009: 300).

The intuitive force of such a claim can be set out in more analytical terms precisely by introducing the foundationally primacy of basic goods and the functional value of basic freedoms. The point can easily be observed also in virtue of the very 'nature' of basic goods. Basic goods are more firm, permanent or constant, and objective (even if not absolutely objective); they are "biological-cum-social" conditions of existence, the universal conditions to secure that everybody can exercise what Miller calls "core human activities" (Miller, 2007, 184).

If one thinks of a situation (social, not individual) where a government has to sacrifice either subsistence or freedom, one can image the possibility (moral-political admissibility) of sacrificing the latter but not the former ${ }^{13}$. We should choose the restrictions of our freedoms for the sake of our own subsistence. Here subsistence may well be interchangeable with security, which seems to be the primary responsibility of any state towards its constituents. Bernard Williams asserts in Hobbesian spirit that the first task of the state (the political) is that of securing order,

${ }^{13}$ An opposing view is sometimes held in situations of war where one ideal (let's call it freedom) is hold even in spite of the very possibility of dying. In these cases, some collectives might choose to disappear rather than surrender. I do not discuss the issue here. It suffices to say that this extreme possibility does not defeat the point (exceptional cases reinforce the general rule). 
protection and safety (Williams, 2005: 3) and that this fundamental 'nature' of the political responds to the preponderance of security over freedoms in those very extreme situations. The claims for global justice are supposed to account for (or be compatible with) this primordial alternative.

Again, the relationship between basic goods and basic freedoms is admittedly tensional and it is true that conflicts between basic goods and basic freedom appear. However, it is also true that, as Miller says, there is "no across-the-board incompatibility between asserting a human right to food and asserting a human right to freedom" (Miller, 2007: 189). Actual conflicts arising between these types of basic rights and the possible resolutions we might find say more about conciliatory alternatives between competing claims in very concrete cases and circumstances than that which any strict theory of rights can say by virtue of an alleged absolute value given to either type of rights.

Evidently, these issues are complex and should be treated in a separate paper. At this point the idea has been to make a case for the interconnectedness of basic goods and basic freedoms in a way that explains both interdependency and the primacy of basic goods, which characterizes the particular idea of global justice in the form of a sufficiency threshold demand ${ }^{14}$.

\section{Bibliography}

Alejandro, R. (1996). “What is Political about Rawls's Political Liberalism?”. The Journal of Politics 58(1): 2-24.

BeItz, C. ([1979]1999) Political Theory and International Relations. Princeton, Princeton University Press.

Beitz, C. (2001). "Human Rights as a Common Concern". American Political Science Review 95 (2).

Caney, S. (2005). Justice Beyond Borders. Oxford: Oxford University Press.

FABrÉ, C. (2007). Justice in a Changing World. Cambridge: Polity.

Gallardo, H. (2000). Política y transformación social: discusión sobre derechos humanos. Quito: SERPAJ.

Miller, D (2005). “Against Global Egalitarianism” In Brock, G. and Moellendorf, D. (eds.) (2005). Current Debates in Global Justice. Dordrecht: Springer.

Miller, D. (2007). National Responsibility and Global Justice. Oxford, Oxford University Press.

Nagel, T. (1991). Equality and Partiality. New York: Oxford University Press.

14 This idea calls for the Rawlsian idea of reflective equilibrium that foresees the possibility of moving at least one degree towards the priority of the good over the right. For an instructive discussion about this matter, see Sandel 1998. 
Nagel, T. (2005). “The Problem of Justice". Philosophy and Public Affairs 33 (2): 113-147.

Nussbaum, M. (2008 [2003]) "Capabilities as Fundamental Entitlements: Sen and Social Justice". In T. Brooks (ed.). The Global Justice Reader. Oxford: Blackwell.

Nussbaum, M. (2006). Frontiers of Justice. London: The Belknap Press.

Pogge, T. (2002). "Cosmpolitanism: a Response". Critical Review of International Social and Political Philosophy 5 (3): 86-91.

Pogge, T. (2002). "Human Rights and Human Responsibilities". In P. De Grieff and

C. Crain (eds.) Global justice: Transnational Politics. Massachusetts:

Massachusetts Institute of Technology.

Pogge, T. (2002). World Poverty and Human Rights. Oxford: Blackwell Publishers. Rawls, J. (1993). Political Liberalism. New York: Columbia University Press.

Rawls, J. (2001). The Law of Peoples. Massachusetts: Harvard University Press.

Rawls, J. ([1971]1999). A Theory of Justice. Massachusetts: Harvard University Press.

Sangiovanni, A. (2008) "Justice and the Priority of Politics to Morality". The Journal of Political Philosophy 16 (2): 137-64.

Satz, D (1999). "Equality of What Among Whom? Thoughts on Cosmpolitanism, Statism and Nationalism". In Brilmayer, L., Shapiro I. (eds.) Global Justice. New York: New York University Press.

Sen, A. (1999) Development as Freedom. Anchor Books: New York.

SEN, A. (2009). The Idea of Justice. London: Penguin Books.

Shue, H. (1980). Basic Rights. New Jersey: Princeton University Press.

Singer, P. (1972) "Famine, Aflluence and Morality" Philosophy and Public Affairs. (1): 229-243.

Singer, P. (2002a) "Poverty, Facts and Political Philosophies: Response to 'More than Charity". Ethics and International Affairs 16 (2): 121-124.

Wenar, L. (2007) "Responsibility and Sever Poverty". In Thomas Pogge (ed.)

Freedom from Poverty and Human Rights. Oxford: Oxford University Press.

Williams, B. (2005). In the Beginning was the Deed. Princeton: Princeton University Press.

Mario Solís Umaña

Escuela de Filosofía

Universidad de Costa Rica

mario.solisumana@.ucr.ac.cr 